\title{
Assessing the impact of the Lexical Approach on EFL perceived oral proficiency: What is the role of formulaic sequences?
}

\author{
Marco Cancino \\ Department of English \\ Andres Bello University, Chile \\ marco.cancino@unab.cl \\ Jonathan Iturrieta \\ Department of English \\ Andres Bello University, Chile \\ j.iturrietaaguero@uandresbello.edu
}

\begin{abstract}
The Lexical Approach (LA) is a pedagogical method that emphasizes authentic language and learner exposure to co-occurring lexical units. The approach has garnered renewed interest over the last years due to its focus on the frequency of multiword form-meaning distributions, which is in line with usage-based (UB) approaches to language acquisition. Thus, the present study sought to assess the impact of the LA on perceived oral proficiency and formulaic sequence use. To this end, 38 English as a Foreign Language adult learners at a language institute were divided into two groups, one of which was exposed to 38 teaching hours of instruction based on LA principles. Both groups were asked to perform two oral tasks that were evaluated by three judges in terms of oral proficiency and number of formulaic sequences used. Results revealed that the LA group outperformed the control group in perceived overall oral proficiency scores and in the number of formulaic sequences used, and that there were positive moderate correlations between these measures. Pedagogical implications emphasizing the importance of exposing learners to lexical chunks by means of authentic materials are discussed, as well as their relevance in EFL contexts that focus on the short-term achievement of grammatical accuracy.
\end{abstract}

Keywords: lexical approach; collocations; formulaic sequences; oral proficiency; EFL learning.

\section{Resumen}

El Enfoque Léxico (LA) es un método pedagógico que pone el énfasis en el lenguaje auténtico y la exposición del alumno a unidades léxicas concurrentes. Este 
enfoque ha ganado un interés renovado en los últimos años debido a su atención en la frecuencia de asociaciones de forma-significado de múltiples palabras, lo que está en línea con enfoques basados en el uso (usage-based) para la adquisición del lenguaje. Por lo tanto, el presente estudio buscó evaluar el impacto del LA en la habilidad oral y el uso de las secuencias de fórmula. Con este fin, 38 estudiantes adultos de inglés como lengua extranjera (EFL) en un centro de idiomas se dividieron en dos grupos, uno de los cuales fue expuesto a 38 horas de enseñanza de instrucción basada en los principios de LA. Se pidió a ambos grupos que realizaran dos tareas orales que fueron evaluadas por tres jueces en términos de competencia oral y número de secuencias de fórmulas utilizadas. Los resultados revelaron que el grupo de LA superó al grupo de control en competencia oral general percibida y en el número de secuencias de fórmula utilizadas, y que hubo correlaciones moderadas positivas entre estas medidas. Se discuten las implicaciones pedagógicas que enfatizan la importancia de exponer a los estudiantes a fragmentos léxicos por medio de materiales auténticos, así como su relevancia en contextos de inglés como lengua extranjera que se centran en la búsqueda de la corrección gramatical a corto plazo.

Palabras clave: enfoque léxico; colocaciones; secuencias de fórmula; competencia oral; aprendizaje del inglés como lengua extranjera.

\section{Introduction}

The lexical approach (henceforth LA) is a pedagogical method introduced by Lewis (1993) that regards language learning as occurring through learners' repeated exposure to authentic, real-life English in the form of multi-word items being taught as wholes. This approach proposes that the internalization of idiomatic and prefabricated structures to understand and produce language is crucial for successful communication. The LA has garnered renewed interest due to its focus on the frequency of form-meaning distributions, an aspect that is shared by usage-based (UB) approaches to language acquisition. The main tenets of UB theories are that language learning takes place incidentally and implicitly (Madlener, 2018), and that this process is influenced by the frequency of form-meaning associations in the input found in social interactions (Ellis, 2013). Thus, UB approaches to language learning underscore the impact of frequency distributions, salience, and contingency of formmeaning associations (i.e., collocations) on second language development (Tyler et al., 2018). The frequency of repetitions can help commit certain form-meaning structures to memory, increase the abstract representations of such constructions, and enhance their productive use (Ellis, 2013; Madlener, 2018). Being part of such "usage events" in repeated, contextualized social interactions is central to usage-based theories (Tyler \& Ortega, 2018). In line with this, pedagogical methods such as the LA have underscored 
the idea that contextualized form-meaning distributions based on repetitions can support second language development.

Lexical chunks are form-meaning distributions that play a significant role in language learning (Wood, 2010). These constructions are also referred to as readymade chunks, multi-word units, and formulaic sequences (Hou et al., 2016). They are fairly common in native and native-like spoken language and thus are seen as a required feature in these linguistic contexts (Appel \& Wood, 2016). Lexical chunks are typically defined as "groups of multiword units of language which are stored in long-term memory as if they were single lexical words" (Hou et al., 2016: 2). Lewis (1997) identified four main types of lexical chunks: words and poly words (e.g., by the way), collocations (e.g., heavy rain), institutionalized utterance frames (e.g., We'll see), and heads (e.g., It is generally acknowledged that...). Since UB approaches do not establish strict boundaries between grammar and lexicon subsystems (Römer, 2009), lexical chunks are seen as "conventionalized form-meaning mappings, the result of repeated use of certain linguistic units and specificity" (Hou et al., 2016: 3). From this perspective, then, lexical chunks are word sequences that can contain variable slots to be filled and used to express a concept in a conventionalized (i.e., formulaic) manner (Smiskova-Gustafsson, 2013). In the LA, learners need to be exposed to a significant stock of lexical chunks, which can be combined to produce "continuous, coherent text" (Lewis, 1993:7). If learners can remember lexical chunks after being exposed to considerable amounts of language (Durrant \& Schmitt, 2010), then using prefabricated language can become a valuable tool in the learning process.

Advocates for the LA argue that classes focusing on learning as a product should be left behind, as teachers need to go beyond delivering content and completing textbook activities that highlight accuracy. Instead, this approach requires learners to engage in the observation of language features, to hypothesize on how such features can be used to communicate, and to experiment with language to communicate successfully. As learners experiment with language, it is likely that they will make grammatical mistakes in their production. These errors are regarded as an intrinsic feature of successful learning processes, as they evidence language development. Accordingly, Lewis (1993) states that learning is "essentially organic and involves connecting new materials to what is already known" (p. 56). Hence, the LA exposes learners to chunks, collocations and idiomatic expressions so that such structures can be internalized and subsequently accessed when needed. Furthermore, Lewis (1993) posited that language is mainly made of "grammaticalized lexis, not lexicalized grammar" (p. vi) and that "grammar as a structure is subordinate to lexis" (p. vii). These statements emphasize the importance of lexical phrases and their predominance over grammatical structures when communication is sought. Lewis argued for the need to remove grammar from 
the central position it had previously held in traditional language learning approaches, and replace it with the use of functions (Lewis, 1993). For example, this would imply a shift from teaching the past simple to asking, "What did you do yesterday?". The lexical syllabus on which these practices must be based includes meaning-making activities that highlight the importance of using the language to acquire it, rather than the mere display of linguistic knowledge (Willis, 1990).

Another essential principle of the LA is the idea that language teaching must be focused on raising learners' awareness towards language chunking and how this impacts comprehension (Lewis, 1993). This implies that learners are expected to experience language and notice its features in context before they can acquire and use those features to communicate. When learning is seen as a process of language experimentation, the focus is not placed on how grammatically accurate an utterance is but on how the message is decoded by the receiver to establish successful communication. Although grammar explanations have been left aside in the implementation of the LA, learners may still notice syntactic patterns and rules as they experiment with language. These patterns may result in grammar formulations created by learners (i.e., grammatical rules such as third person $-s$ ) that must be valued by teachers even when they represent incorrect assumptions (Lewis, 1993).

\subsection{Collocations}

The role that frequent and natural language concordances - i.e., collocations - play in language perception and production is central in the LA approach. Lewis (2000) referred to collocations as "the way in which words co-occur in natural text in statistically significant ways" (p. 132). Shin \& Nation (2008) defined them as "a group of two or more words that occur frequently together, and ... is not restricted to two- or three-word sequences" (p. 4). They also identified two parts in a collocation: "a pivot word which is the focal word in the collocation and its collocate(s), the word or words accompanying the pivot word" (p. 4). For example, in the sequences electricity bill, gas bill and fuel bill, the word bill is the pivot word, which is collocated by electricity, gas and fuel, respectively.

Collocations are a fundamental component of the LA. They play an important role in developing learners' oral proficiency and vocabulary strategies. One of the most important reasons for teaching collocations in language courses is that these structures can help develop fluency and native-like selection of language structures (Shin \& Nation, 2008). This is a goal that, according to Siyanova \& Schmitt (2008), "most advanced learners strive for, in their pursuit of second language proficiency, but few achieve" (p. 431). Benefits to using collocations have been reported by 
Kashahara (2011), who found that EFL learners tend to remember more words when they appear next to other words because they facilitate the activation of already stored structures. However, teaching collocations may be challenging. For example, teachers must form noticing habits in their learners to raise awareness and help them identify word patterns in texts. Collocations must be carefully selected by teachers and must be appropriate and relevant to a particular proficiency level. Furthermore, learners must be encouraged to notice the collocations and guess the meaning of words and multi-word items by means of contextual features. These prefabricated structures are very diverse and can portray specific functions. Therefore, if they are not appropriately selected, they can fail to convey meaning and hinder language development. Boers \& Lindstromberg (2009) suggest that in order to maximize the teaching of collocations, the proficiency level of the students and the aim of the lesson should be considered, as well as the usefulness and the frequency of the chunks.

\subsection{Implementing the LA in the language classroom}

As has been stated, the purpose of the LA is to expose learners to authentic language so as to increase their awareness and internalization of lexical chunks. As this type of input is crucial to the pedagogical process, the way in which teachers select and implement classroom materials plays a significant role in the approach. With respect to vocabulary sources, Vasiljevic (2014) highlights the importance of using dictionaries to learn about word sequence meanings and usages, along with training learners to use these tools regularly. Vocabulary learning materials should help learners in two important areas. First, materials must present learners with frequent practice of appropriate vocabulary in natural contexts, according to their language needs. Second, learners should adopt vocabulary learning techniques and strategies that can be used outside the classroom and in real language settings (McCarten, 2007). As Lewis (1993) argued, instead of using material specifically tailored for learners, there are "real materials" (p. 186) such as songs, TV programmes, and videos, that teachers can use to introduce lexical chunks. In the LA, the main role of teachers in this respect is to provide students with these materials to increase their awareness of how prefabricated structures are frequently used. Although non-native writers tend to overuse high-frequency collocations and underuse low-frequency ones (Durrant \& Schmitt, 2009), elementary level learners can benefit from being exposed and using the former structures within an LA methodology. Furthermore, if long-term acquisition is facilitated by materials that are only partially understood (Lewis, 1993), it follows that real, authentic materials fit well in the LA. Nonetheless, Lewis (1993) warns that supplementary materials need to be prepared to support learning with authentic sources. 
Lewis put forward a number of suggestions on how to tackle LA principles in the classroom. The LA requires that most of the classroom time be devoted to two important aspects in the approach: exposing learners to all types of multi-word items and raising their awareness of how language is used. In line with UB approaches, focusing on these aspects does not mean disregarding form, grammar, or creative use of language (Lewis, 1997). Teachers are allowed to address learners' questions about grammar patterns, but real-language materials have priority over descriptions on how language works (Lewis, 1993). In order for learners to acquire long-term grammatical accuracy, real-language awareness is heightened to make them notice collocational patterns instead of having teachers explain the underlying syntactic patterns. Authentic classroom language is vital in early lessons; common classroom-related chunks must be frequently used by the teacher so that leaners can familiarize with them and internalize them for later use. Expressions such as "Sorry, I don't know" and "Sorry, I can't remember", and sentence heads such as "Did you..." or "Have you ever..." are suggested in the approach. They must be taught as a whole and with no analysis at the word level. At early stages, teachers must emphasize language comprehension rather than production (Lewis, 1997). That is, teachers should not expect learners to use the prefabricated structures from the outset but should instead facilitate their repeated processing and understanding each time learners are exposed to them. As Lewis (1993) stated, "a short piece of real material, listened to several times is much more likely to be effective than a longer piece listened to once" (p. 186).

Lackman (2011) argues that words should not be taught without context in the LA. If lexical items are taught in isolation, it is less likely for those words to become part of the internalized chunk storage that teachers should seek to build. Lackman goes on to argue that idioms should not take up a large part of the lessons, as they are not commonly used by English speakers in real-life situations. In addition, encouraging a focus on collocation by means of dictionaries can lead to a successful implementation of the approach. Finally, Lackman suggests activities that can facilitate the implementation of the LA in the language classroom. Among these, the "Find someone who..." activity encourages students to find people who meet the requirements given in certain statements. For example, the teacher can ask students to look at a poster with famous people and ask them: "Find someone who has written books". Learners should then identify a particular person based on the descriptions. Another useful activity is "Giving clues", which requires the teacher to provide features of a lexical chunk so that learners can look for the structure that fits the description in the materials. For example, if the teacher asks for "a collocation made by a verb plus a noun", learners must underline "have dinner" in the printed material. Finally, "slot-fillers" can be used so that learners become aware of specific structures in multiword items. Slot-filler prompts such as "What did you " can be completed with 
many verb forms and adverbs: "What did you do yesterday?", "What did you eat last night?" (Lackman, 2011).

\subsection{Previous studies on the Lexical Approach}

Several studies have been carried out to investigate the effectiveness of the LA in the second language classroom. These studies have assessed the impact of exposing language learners to collocations and chunks on their written and oral production. The evidence provided by the literature comes from diverse contexts and is based on collocation-oriented perspectives applied in such settings. Research on the impact of the LA with a focus on formulaic sequences on college students' oral proficiency was conducted by Boers et al. (2006). The authors refer to formulaic sequences as "words or word string which appear to be processed without recourse to their lowest level of composition" (Wray, 2002: 4), and include other categories such as collocations, phrasal verbs, and idioms. Their 22-hour study consisted of an experimental group receiving exposure to real language and substantial amounts of authentic materials to enhance receptive skills (listening and reading) by means of phrase-noticing. The control group was taught in traditional lessons that differentiated grammar from vocabulary activities. Learners' performance in both groups was recorded and rated by judges. Results revealed that higher scores in perceived oral proficiency were obtained by students who were exposed to the LA. Boers et al. (2006) concluded that formulaic sequence instruction provides learners with sufficient vocabulary storage to allow them to store these multi-word items and retrieve them for immediate use. Similar results were reported by Stengers et al. (2011), who found a positive correlation between the frequency of formulaic sequence use by 60 Modern Languages students in Belgium and their level of oral proficiency. Wood (2006) conducted research on 11 English as a second language (ESL) learners to investigate the functions of formulaic sequences in speech fluency. He found that using these structures helped learners increase the range and use of functions when narrating stories. Similar findings were reported by Jones et al. (2015), who analyzed the chunks found in the spoken language of higherintermediate level students. The oral production of 32 participants was assessed in terms of pronunciation, grammatical aspects, lexis, speech management, and ability to interact with language. Findings showed that the most frequent chunks used by learners at this proficiency level were often comparable to the chunks produced by native speakers, according to corpus data. Learners also used multi-functional chunks (e.g., I think) to convey a variety of meanings. The authors conclude that lexical chunks are more frequent at higher oral proficiency levels, and that teachers should focus on multi-functional chunks that can cover a wider range of meanings. 
Balcı \& Çakır (2012) reported positive effects when teaching vocabulary using collocations in a Turkish EFL classroom. The experimental group in their study was taught vocabulary by means of collocations, whereas the control group was taught with a traditional approach to vocabulary learning (i.e., by means of synonyms, antonyms, and definitions). Results suggested that vocabulary retention was higher in the group that was exposed to collocations. It must be noted that although learners usually create language patterns by means of collocations, these are not always accurate. According to Kuo (2009), learners make errors when selecting synonyms from the dictionary. When these synonyms do not collocate with the following word in a multi-word item, the resulting meaning becomes difficult or impossible to understand. These results are in line with Forteza et al. (2009), who found that learners tend to use synonyms to form incorrect collocations, which can hinder comprehension. Indeed, dictionary use may be insufficient if learners are only required to translate isolated words with no processing of the entire collocation. Focusing on L2 writing skills, Tang (2012) divided 85 second-year college students into an experimental (LA) group and a control group to gauge the impact of the LA on writing skills. Results revealed that LA is more effective in improving writing quality (measured by rating scores), as learners gather and internalize features from language and use them to produce written output. Thus, LA instruction allowed these learners to notice the existing gaps between the way they communicate and how native speakers typically perform. Tang concludes that exposing learners to prefabricated lexical sequences to communicate can reduce the number of incorrect sentences in written production, which can in turn increase accuracy and authenticity in the output.

Learners' perceptions in relation to the importance of teaching and learning collocations have also been reported in the literature. In this respect, Wu (2015) investigated the effect that teaching collocations has on the perceptions of elementarylevel EFL students. Overall, findings showed that most participants reported positive attitudes toward the explicit teaching of collocations in the classroom. Learners stated that they felt more motivated to acquire new language structures, and that they acknowledged their own lack of interest toward words that are frequently accompanied by other words. In addition, they stated that it was confusing for them to understand why only certain words were followed or preceded by others (e.g., "powerful" preceding "engine" instead of "strong", even though both words are synonyms). They were aware of the instructor's efforts to encourage practice with the structures and to lower anxiety levels, which highlights the role that teachers play in the implementation of an approach that focuses on collocations. On the other hand, there were students who argued that while the concordance tools provided by the teacher throughout the treatment (e.g., collocation dictionaries and language databases) were helpful, they still found it problematic to use them because they were presented entirely in the L2. 
Indeed, no access to L1 materials can confuse and frustrate learners at early stages of language development, and teachers should prepare supplementary materials to compensate for this. Overall, the reviewed studies underscore the value in teaching prefabricated sequences. Research findings suggest that this type of instruction should be implemented by language teachers to support learning and that researchers should continue to evaluate its impact on proficiency.

\section{Research Methodology}

The present study aims at assessing the impact of the Lexical Approach (LA) on adult EFL learners' perceived oral proficiency. The research questions are as follows:

1 What is the impact of the LA on the perceived oral proficiency of adult EFL learners?

2 What is the impact of the LA on the number of formulaic sequences used by these learners?

3 What is the relationship between perceived oral proficiency and the number of formulaic sequences used by these learners?

Research question 1 sought to explore how adult EFL learners use formulaic sequences in instructed communicative settings as part of the LA and to characterize the impact of teaching such sequences on their perceived oral proficiency (Boers et al., 2006; Millar, 2010). Research question 2 aimed at finding whether the LA would increase the number of lexical chunks produced by learners exposed to the LA. Finally, research question 3 sought to establish a relationship between the frequency of formulaic sequences used by these learners and their perceived oral proficiency (Stengers et al., 2011). The three research questions aimed at gauging the pedagogical strength of the lexical approach and contributing to the empirical evidence for the efficacy of UB approaches in EFL (Tyler et al., 2018).

The present study adopted a quasi-experimental design that included an intervention of 38 teaching hours over a four-month span. An experimental (LA) group and a control group were set up for the study, and a teacher in each group was instructed to adopt a particular teaching approach. Following Boers et al. (2006), the LA group was taught by means of formulaic expressions including lexical items, chunks, and collocations through real-language materials. The control group was exposed to regular lessons that took the same amount of teaching hours and were based on grammatical explanations, grammatical feedback, self-explanatory grammatical 
handouts, worksheet completion, and general textbook activities. Collected data was analyzed to assess the impact of the LA on perceived oral proficiency, on the number of formulaic sequences utilized by learners, and on the relationship between the number of formulaic sequences used by learners and their oral proficiency.

\subsection{Participants}

The participants were 38 students ( 25 males and 13 females) in two intact adult EFL classes at a professional institute. Each class consisted of 19 EFL students who were enrolled in a compulsory elementary EFL course as part of their computer engineering programme. Their ages ranged from 18 to 25 years old, and their CEFR (Common European Framework of References for Languages) oral proficiency level was elementary English (A2), as measured by a final oral exam completed at the end of their previous course. The EFL courses in the institute sought to enhance students' communicative skills to further career development.

\subsection{Treatment}

The experimental group (LA) was taught using LA principles based on cooccurring lexical units, whereas the control group received regular lessons. Both groups were taught the same contents, as stated in the course syllabus. In the LA group, Lackman's (2011) suggestions were followed. Authentic materials such as published songs, newspapers and TV show videos were used, and learners were not exposed to worksheets with grammatical explanations. As can be seen in the sample activities (Appendix), classroom tasks such as "Find somebody who..." were adapted and implemented in the LA group. Students were given songs and asked to look for a sentence that would fit the linguistic clue given by the teacher. Songs are "a rich source of lexical items, particularly commonly used semi-fixed expressions" (Lackman, 2011: 13). Slot-fillers were also implemented in the LA group. For example, group conversations about past experiences were held by using ready-made slot-fillers on the whiteboard. Structures such as "Did you ______ last weekend?" and "Where did you yesterday?" were used to provide learners with sufficient language to ask questions to their classmates. Learners answered these questions by means of slot-fillers such as "Yesterday, I ___.". The use of dictionaries was also encouraged as learners completed the lexical slots. As indicated by Lewis (1993), learners were asked to keep a vocabulary notebook and jot down useful phrases and words. Learners were advised to divide the notebook into sections (e.g., "giving directions" and "giving opinions") so that they could find new expressions and collocations more easily. They were also given a list with the vocabulary items reviewed in the lessons and were told to include them 
in their notebooks. Learners in the LA group were encouraged to notice language features in every piece of authentic language to which they were exposed and to look up those lexical chunks in a dictionary. Drawing from Hsu \& Chiu (2008), direct instruction of lexical collocations was implemented in the LA group, as it was found to be beneficial when attempting to teach vocabulary.

Although a coursebook was used to deliver the lessons in both the treatment and control groups, the approach taken with it was tailored to each condition. In the LA group, the activities chosen from the coursebook were carefully tailored to follow LA principles. Thus, coursebook sections that were directly related to grammar explanations were taken out, as syntactic patterns are expected to be noticed, but not explained to learners in the LA. In addition, "unauthentic" dialogues (Aston, 2009) were replaced with real-world materials. In the control group, learners had access to coursebooks, handouts and e-classes with summarized versions of every unit, L1 explanations, and content activities. The control group completed all the activities in the coursebook, which included sections such as the "grammar bank" - where grammatical structures are explicitly provided to students - and the "vocabulary bank" - where lists of isolated words reviewed in the lesson are presented. Furthermore, both groups differed in terms of the increased awareness toward lexical chunks in the activities completed by the LA (experimental) group. Teacher feedback in both groups was focused on providing meanings to single or multi-word structures, but participants in the LA group were asked to contextualize such meanings as part of lexical chunks. As reported by the teachers, the LA group did not spend more time on oral practice than the control group, as both teachers included between 15 and 20 minutes of conversational practice per lesson. However, the oral practice in the LA group was based on authentic materials (i.e., songs and videos), while the control group focused on practicing grammar structures. Table 1 below summarizes the type of materials and approaches implemented in both groups. 
Table 1. Approaches and type of materials in the LA group and the control group

\begin{tabular}{|c|c|c|}
\hline Group & LA Group & Control group \\
\hline $\begin{array}{l}\text { Materials (both groups } \\
\text { were exposed to the same } \\
\text { course content) }\end{array}$ & $\begin{array}{l}\text { Coursebook (vocabulary } \\
\text { activities with the LA } \\
\text { approach), notebook } \\
\text { for useful phrases and } \\
\text { sentences. }\end{array}$ & $\begin{array}{l}\text { Coursebook (vocabulary } \\
\text { and grammar activities) } \\
\text { and handouts. }\end{array}$ \\
\hline Approach to grammar & $\begin{array}{l}\text { No explicit focus on } \\
\text { grammar. }\end{array}$ & $\begin{array}{l}\text { Explicit treatment of } \\
\text { grammar explanations and } \\
\text { grammatical patterns. }\end{array}$ \\
\hline Activities & $\begin{array}{l}\text {-Authentic materials (i.e. } \\
\text { songs, newspapers, videos). } \\
\text {-Example of activity with a } \\
\text { song: Students must find a } \\
\text { sentence where the singer } \\
\text { asks where something is. } \\
\text {-Slot fillers (see Appendix). } \\
\text {-Repeated exposure to } \\
\text { lexical chunks. } \\
\text {-Suggested vocabulary. } \\
\text {-Oral practice with } \\
\text { selected lexical chunks. }\end{array}$ & $\begin{array}{l}\text {-Non-authentic material } \\
\text { based on the coursebook: } \\
\text { A: Hello. } \\
\text { B: Hello. } \\
\text { A: What are you doing? Are } \\
\text { you listening to music? } \\
\text { B: No, I am not. } \\
\text { A: Are you cooking? } \\
\text { B: No, I am not. } \\
\text {-Grammar bank. } \\
\text {-Grammar worksheets. } \\
\text {-Coursebook vocabulary } \\
\text { activities. } \\
\text {-Oral practice with } \\
\text { grammar points. }\end{array}$ \\
\hline
\end{tabular}

\subsection{Procedures}

\subsubsection{Oral tests}

As a pre-test measure to control for oral proficiency, we considered a final oral exam (oral assessment) that the participants completed at the end of the previous course level. This oral assessment required learners to complete a 10-minute interview with the teacher about coursebook topics. The rubric assessed range of oral expression, accuracy, and fluency, and the scores were used by the teacher as a final course grade for the learners. A Mann-Whitney $U$ test was run to confirm that the oral proficiency of both groups was similar at the start of the treatment. The scores were not found to be significantly different $(p>.05)$. 
Before collecting post-test oral proficiency data, we secured consent from participants in the study. We provided them with an information sheet where the study was described, and anonymity and confidentiality issues were discussed. They were also told that they could withdraw from the study at any point in the data collection procedures. Once the consent forms were collected, participants completed the 38 weeks of treatment and then were asked to sit an oral test interview carried out by their teacher. A second teacher was present in the room to record the oral test. Participants were assessed individually in 10-minute sessions, which were divided into two tasks. In Task 1, learners had to role-play a situation in which they had to provide directions. Learners had to use a map to indicate how to get from one point to several other points. The teacher gave learners one minute to look at the map in order for them to get acquainted with the names of the streets and locations before giving directions. Task 2 required learners to answer questions using time expressions included in the vocabulary that was taught in the course, and to talk about a topic of their choice.

\subsubsection{Judges and rubrics}

The oral performance data was assessed by three judges. The judges were two native speakers of English who worked as EFL teachers in language institutes and an experienced non-native EFL teacher. The two native speakers of English (Judge A and Judge B) were asked to assess the oral proficiency of participants using two different CEFR rubrics (Council of Europe, 2001). The first rubric focused on qualitative aspects of spoken language and was used by the judges to assess learners' performance considering range of expression, accuracy, and fluency. This measure has been used in other studies addressing perceived learners' oral proficiency (Boers et al., 2006; Stengers et al., 2011). The second rubric measured overall spoken production, which provided a more holistic assessment of the recordings. Each of the components in the rubrics had the same weight in the ratings provided by the judges. Using the mean scores for the components in both rubrics, Judge A and Judge B had to assign a final numeric score that represented the CEFR level attained by a participant (from 1-3 for A1, to 15-18 for C2). Finally, the experienced non-native EFL teacher (Judge Y) was given a checklist sheet and was asked to list and count the formulaic sequence tokens identified in the participants' recordings. Following Boers et al. (2006), Judge Y was asked to count the formulaic sequences without making any judgements on their complexity, because doing so would bring about qualitative aspects that are difficult to assess objectively. She was familiar with the concept of formulaic language and with the literature on lexical chunks, and she did not know whether the participants belonged to the experimental or the control group. 
Two reliability measures were adopted regarding the scores provided by the judges. With respect to the oral proficiency scores provided by Judge A and Judge B, intraclass correlation coefficients were calculated. They were found to be over .96 across all components, which showed that the judges were highly consistent in the scores they provided. Hence, an average score between Judge A and B was computed and considered for analysis. Likewise, an overall proficiency score for Task 1 and Task 2 was computed and taken as a measure of oral proficiency. In order to provide a measure of intra-rater reliability for Judge Y, three weeks after her first formulaic sequence count, she was asked to go through the process again. The intraclass correlation coefficient for the formulaic sequence counts (.938) suggested excellent reliability.

\section{Results}

\subsection{Descriptive statistics for oral proficiency scores}

Table 2 displays descriptive statistics for oral proficiency scores (range of expression, accuracy, fluency, and overall proficiency) in both groups, as perceived by both judges (Judge A and Judge B) as an average for both tasks (Task 1 and Task 2). The means in the control group for all measures were more than doubled in the experimental group. As data did not display normal distribution, the median (Mdn) and the interquartile range (IQR) were used as measures of central tendency and dispersion. Across measures, the medians in the LA group were considerably higher than in the control group. The medians for specific measures in the control group ranged from 3.75 to 4.5 , while the same medians in the LA group ranged between 9.75 and 11.25.

Table 2: Descriptive statistics for oral proficiency scores across measures and groups

\begin{tabular}{llcccccc}
\hline Group & Measures & $\mathrm{N}$ & Minimum & Maximum & Mean & Mdn & IQR \\
\hline LA & TASKS_RANGE & 19 & 5.5 & 17.75 & 10.82 & 11.25 & 5.75 \\
& TASKS_ACC & 19 & 5.25 & 15.75 & 10.07 & 9.75 & 4.75 \\
& TASKS_FLU & 19 & 5 & 17.75 & 10.53 & 10.75 & 5.75 \\
& TASKS_OVERALL & 19 & 4.50 & 16.75 & 10.12 & 10.00 & 5.5 \\
\multirow{5}{*}{ Control } & TASKS_RANGE & 19 & 1 & 12.25 & 5.16 & 4.5 & 5.25 \\
& TASKS_ACC & 19 & 1.25 & 12.75 & 4.9 & 3.75 & 4.5 \\
& TASKS_FLU & 19 & 1.25 & 11.25 & 4.84 & 4.25 & 3.5 \\
& TASKS_OVERALL & 19 & 1.25 & 11 & 4.93 & 5 & 4 \\
\hline
\end{tabular}

RANGE: Range of expression. ACC: Accuracy. FLU: Fluency. OVERALL: Overall oral proficiency. 


\subsection{Mann-Whitney $U$ tests for overall judge scores}

To test whether oral proficiency scores were statistically different in both groups across oral proficiency measures (Tasks 1 and 2) provided by the average proficiency scores (Judges A and B), Mann-Whitney $U$ tests were run (Table 3). Results revealed that the differences in perceived oral proficiency between both groups were statistically significant in specific and overall measures $(p<.05)$.

Table 3: Mann Whitney $U$ tests for average oral proficiency scores across measures

\begin{tabular}{lcccc}
\hline Variable & $\mathrm{U}$ & $p$ & $\begin{array}{l}\text { Mean rank } \\
\text { LA group }\end{array}$ & $\begin{array}{l}\text { Mean rank } \\
\text { control group }\end{array}$ \\
\hline Range & 46.5 & .000 & 26.55 & 12.45 \\
Accuracy & 45.5 & .000 & 26.61 & 12.39 \\
Fluency & 41 & .000 & 26.84 & 12.16 \\
Overall & 53.5 & .000 & 26.18 & 12.82 \\
\hline
\end{tabular}

\subsection{Descriptive statistics for the formulaic sequence count}

Descriptive statistics for the formulaic sequences (FSs) identified by Judge $\mathrm{Y}$ in both groups were computed considering the two tasks as separate measures (Table 4 below) because they revealed higher means and medians for the FSs in both groups in Task 1 (giving directions) in comparison to Task 2 (answering questions and selfselected topic). Thus, both groups found it more difficult to produce FSs in Task 2, regardless of group condition.

Table 4: Descriptive Statistics for formulaic sequence count

\begin{tabular}{lccccccc}
\hline Group & TASK & N & Minimum & Maximum & Mean & Mdn & IQR \\
\hline \multirow{2}{*}{ LA } & 1 & 19 & 3 & 7 & 5.26 & 5.00 & 2 \\
& 2 & 19 & 1 & 3 & 2.16 & 2.00 & 1 \\
\multirow{2}{*}{ Control } & 1 & 19 & 3 & 6 & 4.32 & 5.00 & 2 \\
& 2 & 19 & 1 & 4 & 1.89 & 2.00 & 1 \\
\hline
\end{tabular}




\subsection{Mann Whitney U tests for Judge Y's FS counts}

We further explored the difference in medians for Task 1 and Task 2 reported above by means of Mann-Whitney $U$ tests. As can be seen in Table 5, statistical analysis yielded different results depending on the task being assessed. Results in Task 1 display a significant difference in the FS counts between both groups $(p=.019)$, with a moderate effect size $(r=0.38)$. This difference between groups did not reach significance in Task $2(p<.05)$.

Table 5. Mann Whitney U tests for Judge A's FS counts in both groups

\begin{tabular}{lccccc}
\hline Judge & Task & $\mathrm{U}$ & $p$ & Mean rank LA group & Mean rank control group \\
\hline $\mathrm{Y}$ & 1 & 103 & .019 & 23.58 & 15.42 \\
$\mathrm{Y}$ & 2 & 142 & .220 & 21.55 & 17.45 \\
\hline
\end{tabular}

\subsection{Correlations between overall oral proficiency scores and formulaic sequence counts}

This section presents the correlations performed between the overall oral proficiency scores (Task 1 and Task 2) of participants as perceived by Judges A and $\mathrm{B}$ (average score) and the mean number of FSs counted by Judge $\mathrm{Y}$ in those tasks. These correlations sought to assess the extent to which the improvement in terms of oral proficiency is related to the number of FSs produced by the participants. For this purpose, Spearman rank tests were run, as data was found to be non-parametric. Table 6 shows that moderate significant positive correlations between the number of FSs counted and oral proficiency scores were found. These correlations ranged from .478 (range of expression and FS counts) to .497 (fluency and FS counts).

Table 6. Spearman's rho correlations between average oral proficiency score measures and FS counts

\begin{tabular}{ccccc}
\hline & RANGE & ACC & FLU & OVERALL \\
\hline FSC &, $478^{*}$ &, $491^{*}$ &, $497^{*}$ &, $478^{*}$ \\
\hline
\end{tabular}

FSC: Formulaic sequence count. RANGE: Range of expression. ACC: Accuracy. FLU: Fluency. OVERALL: Overall oral proficiency.

${ }^{*}$ Correlation is significant at the 0.01 level (2-tailed). 


\section{Discussion}

\subsection{What is the impact of the LA on the perceived oral proficiency of adult EFL learners?}

The first research question aimed to assess the impact of the LA on learners' perceived oral proficiency. Results revealed that participants' oral proficiency scores were significantly higher in the LA group, which suggests that the implementation of the LA principles in the treatment condition had a positive effect on learners' oral proficiency scores in terms of range of expression, fluency, and accuracy. These results are in line with Boers et al. (2006) and Stengers et al. (2011), who reported higher oral proficiency scores in those components when learners were taught using formulaic expressions. The number of lexical chunks delivered through authentic language in the LA group may have raised learners' awareness toward those structures and facilitated their use when producing more accurate and fluent language (Boers \& Lindstromberg, 2009; Lewis, 1997). These results also contribute to the literature reporting the positive effects of teaching formulaic sequences and collocations on the development of fluency and a native-like selection of structures (Shin \& Nation, 2008; Wood, 2006, 2010). In particular, the perceived oral proficiency scores given by Judges $\mathrm{A}$ and $\mathrm{B}$ in the present study may have been influenced by the native-like selection of lexical chunks done by participants in the LA group. Results are also in line with Serrano et al. (2015), who found that lower and intermediate level learners benefit the most from formulaic sequence instruction.

\subsection{What is the impact of the LA on the number of formulaic sequences used by these learners?}

The second research question sought to measure the impact of the LA on the number of formulaic sequences used by these participants in the tasks. Significant differences were found in Task 1, where the LA group outperformed the control group on the number of FSs used to give directions. Although the number of formulaic sequences produced in Task 2 was higher in the LA group, this difference was not significant. These results can be discussed in terms of the impact of the type of task on participants' performance. Boers et al. (2006) reported that their participants performed differently according to the task they were facing (conversation about a magazine article and spontaneous conversation about a familiar topic). In line with the findings in the present study, Boers et al. found that participants used more formulaic expressions in the LA group when they were engaged in a conversation about a magazine article. Their participants may have been able to notice lexical chunks and use them 
when discussing the magazine article because they were given time to read it. This also happened in Task 1 (Giving directions) in the present study, as participants were given some time to look at the map and get acquainted with the streets and landmarks before starting the role-play task. While Task 1 addressed role-play practice with more specific and predetermined sequences for learners to use, Task 2 was less specific in this respect and required learners to speak about a topic they had just chosen and without preparation. Thus, participants may have produced fewer formulaic sequences in Task 2 because in Task 1 they had time to process specific lexical chunks and their language did not require complex lexical or syntactic modifications to be successfully used (turn left, turn right, go straight ahead). This seems to be in line with findings suggesting that producing formulaic sequences has a processing advantage over language that is generated through speakers' creativity (Conklin \& Schmitt, 2008). Furthermore, awareness raising is one of the most important features in the LA (Lewis, 1993), so it can be argued that the non-significant results found in Task 2 may be due to the limited number of hours devoted to this kind of task. As Rafievan (2018) argues, "classroom time is clearly too limited to explicitly teach more than a fraction of the vast number of formulaic sequences in language" (p. 2). Indeed, the amount of time devoted to the LA and its features must aim at long-term objectives to achieve successful implementation. The treatment in the present study included 38 hours of LA practice, while Boers et al.'s intervention (2006) consisted of 22 hours. Still, a more comprehensive approach to formulaic sequences might provide more measurable differences with respect to spontaneous speaking tasks.

\subsection{What is the relationship between perceived oral proficiency and the number of formulaic sequences used by these learners?}

The third research question aimed at assessing the relationship between the participants' perceived overall oral proficiency (rated by Judges A and B) and the number of formulaic sequences they used (counted by Judge Y). Findings revealed moderate positive correlations across all components of oral proficiency; that is, the higher the number of formulaic sequences used in the tasks, the higher the oral proficiency scores given by the native-speaker judges. Overall, the perceived proficiency level of participants was found to be related to the number of formulaic sequences produced by them, results that are in line with Stengers et al. (2011). The findings of the present study are also in line with Wood (2006), who found that participants who performed better in fluency measures tended to use more formulaic sequences in their speech. These findings indicate that mastering ready-made structures when learning a new language will likely increase perceived oral proficiency. 


\section{Conclusion}

In the present study, three main findings can be reported in relation to the LA and its effects on oral proficiency and FSs. First, the implementation of the LA based on frequent exposure to form-meaning associations advocated by UB approaches (Tyler et al., 2018) was found to have a positive impact on the development of learners' oral proficiency as perceived by native-speaker judges. Thus, language development can be, to some extent, promoted by repeated exposure to authentic language and awareness raising toward lexical bundles. Second, LA principles can influence the development of a formulaic sequence repertoire in learners, particularly in the production of specific lexical chunks. Even though the LA group outperformed the control group in terms of formulaic sequence counts in both tasks (giving directions and questions and answers/ talk about), this difference only reached significance in Task 1, where participants were asked to give directions using a map. This finding highlights the importance of allocating enough practice time to the development of a multi-word vocabulary repertoire in learners that can be retrieved for spontaneous talk. Finally, the moderate correlations found suggest that there is a relationship between the number of formulaic sequences used and perceived oral proficiency. In other words, using more formulaic sequences will likely increase the perceived oral proficiency score of a learner. This analysis was done by focusing on the number of formulaic sequences produced (see Boers et al., 2006) rather than on their complexity (i.e., length of the formulaic sequence), due to the limited oral proficiency in these learners. For this reason, a straightforward measure of frequency was selected over a total number of words/words in FS ratio (cf. Hou et al., 2016). Nonetheless, the inclusion of complexity measures in future studies could yield additional data characterizing the use of formulaic sequences in higher proficiency level learners. In addition, although written production was not assessed in the present study, it is likely that repeated exposure to lexical chunks can have a positive impact on the written output of learners when compared to translating isolated words from a dictionary (Forteza et al., 2009; Kuo, 2009). However, studies should include linguistic measures of written output (i.e., syntactic complexity) that go beyond holistic rubrics (see Cancino \& Panes, 2021) to assess specific aspects of proficiency and confirm the impact of the LA on written production.

\subsection{Implications for pedagogy}

The pedagogical implications of the findings in the present study can be addressed in terms of the effectiveness of a teaching approach that is based on LA principles. The treatment group was exposed to 38 hours of LA instruction, and results provide evidence highlighting the benefits of teaching language items as wholes, rather than spending most of the classroom time on grammar explanations (as was the case in the 
control group). However, it would seem that fully applying LA principles in contexts that focus on the short-term achievement of grammatical accuracy may become problematic. That is, a primary focus on grammar accuracy will likely disregard the emphasis on long-term internalization of lexical chunks by means of authentic materials proposed by the LA approach. Some level of accuracy is necessary to achieve comprehensibility in the LA, but this is neither essential nor expected at early stages of second language development. This stance is in accordance with the more implicit approach to grammar advocated by usage-based pedagogies (Tyler et al., 2018). Moreover, the limited potential exposure to multi-word form-meaning structures that EFL learners in the selected context receive (i.e., two 90-minute lessons a week) hinders the opportunities for noticing and processing lexical chunks. Therefore, EFL teachers need to maximize their learners' practice with these structures so that the time between each exposure is reduced and internalization can take place (Serrano et al., 2015).

The present study contributes to the evidence showing that instruction focusing on raising awareness toward co-occurring lexical units can increase oral proficiency over time. This awareness towards lexical chunks can be boosted by exposing learners to authentic language materials, rather than to the sheltered materials typically found in textbooks. Furthermore, natural rhythm in speech is more likely to be found in the real-life language presented in teaching methodologies based on the LA, which can increase awareness toward authentic speech patterns. As the LA requires learners to notice patterns and experiment with them without engaging in short-term grammar assessment (Lewis, 1993), long-term goals for the teaching of formulaic expressions need to be set if the approach is to yield oral proficiency development.

\section{References}

Appel, R., \& Wood, D. (2016). Recurrent word combinations in EAP test-taker writing: Differences between high- and low-proficiency levels. Language Assessment Quarterly, 13, 55-71.

Aston, G. (2009). Corpora and language learners. Amsterdam: Benjamins.

Balcı, Ö., \& Çakır, A. (2012). Teaching vocabulary through collocations in EFL Classes: The case of Turkey. International Journal of Research Studies in Language Learning, $1(1), 21-32$.

Boers, F., Eyckmans, J., Kappel, J., Stengers, H., \& Demecheleer, M. (2006). Formulaic sequences and perceived oral proficiency: Putting a lexical approach to the test. Language Teaching Research, 10(3), 245-261. 
Boers, F., \& Lindstromberg, S. (2009). Optimizing a lexical approach to instructed second language acquisition. Hampshire, UK: Springer.

Cancino, M., \& Panes, J. (2021). The impact of Google Translate on L2 writing quality measures: Evidence from Chilean EFL high school learners. System. Advance online publication.

Conklin, K., \& Schmitt, N. (2008). Formulaic sequences: Are they processed more quickly than nonformulaic language by native and nonnative speakers? Applied Linguistics, 29, 72-89.

Council of Europe. (2001). Common European framework of references for languages. Learning, teaching, assessment. Cambridge: Cambridge University Press.

Durrant, P., \& Schmitt, N. (2009). To what extent do native and non-native writers make use of collocations? International Review of Applied Linguistics, 47, 157-177.

Durrant, P., \& Schmitt, N. (2010). Adult learners' retention of collocations from exposure.Second Language Research, 26, 163-188.

Ellis, N. C. (2013). Construction grammar and second language acquisition. In T. Hoffmann \& G. Trousdale (Eds.), The Oxford handbook of construction grammar (pp. 365-378). New York: Oxford University Press.

Forteza, R., Prahlad, S. R., Rubtsova, E., \& Sabitov, O. (2009). Collocations in the vocabulary English teaching as a foreign language. Acimed, 19(6), 1-5.

Hou, J., Loerts, H., \& Verspoor, M. H. (2016). Chunk use and development in advanced Chinese L2 learners of English. Language Teaching Research, 22(2), 148-168.

Hsu, J.-Y., \& Chiu, C.-Y. (2008). Lexical collocations and their relation to speaking proficiency of college EFL learners in Taiwan. Asian EFL Journal, 10, 181-204.

Jones, C., Waller, D., \& Golebiewska P. (2015). Spoken lexical chunks used by successful learners at B2 level: Forms and functions. CALR Linguistics Journal, 1-13.

Kasahara, K. (2011). The effect of known-and-unknown word combinations on intentional vocabulary learning. System, 39, 491-499.

Kuo, C. (2009). An analysis of the use of collocation by intermediate EFL college students in Taiwan. ARECLS, 6, 141-155.

Lackman, K. (2011). Lexical Approach Activities. Ken Lackman \& Associates Educational Consultants. Retrieved from http://kenlackman.com/files/ LexicalActivitiesBook102.pdf

Lewis, M. (1993). The lexical approach: The state of ELT and a way forward. Hove: Language Teaching Publications. 
Lewis, M. (1997). Implementing the lexical approach: Putting theory into practice. Language. Hove: Language Teaching Publications.

Lewis, M. (2000). Teaching collocation: Further developments in the lexical approach. Hove: Language Teaching Publications.

Madlener, K. (2018). Do findings from artificial language learning generalize to second language classrooms? In A. Tyler, L. Ortega, M. Uno, \& H.I. Park (Eds.). Usage-Inspired L2 Instruction (pp. 211-234). Amsterdam: John Benjamins Publishing Company.

McCarten, J. (2007). Teaching vocabulary: Lessons from the corpus, lessons for the classroom. New York: Cambridge University Press.

Millar, N. (2010). The processing of malformed formulaic language. Applied Linguistics, 32, 129-148.

Rafieyan, V. (2018). Role of knowledge of formulaic sequences in language proficiency: Significance and ideal method of instruction. Asian-Pacific Journal of Second and Foreign Language Education, 3(1), 1-23.

Römer, U. (2009). The inseparability of lexis and grammar. Annual Review of Cognitive Linguistics, 7, 140-162.

Serrano, R., Stengers, H., \& Housen, A. (2015). Acquisition of formulaic sequences in intensive and regular EFL programmes. Language Teaching Research, 19(1), 89-106.

Shin, D., \& Nation, P. (2008). Beyond single words: The most frequent collocations in spoken English. ELT Journal, 62(4), 339-348.

Siyanova, A., \& Schmitt, N. (2008). L2 learner production and processing of collocation: A multi-study perspective. Canadian Modern Language Review, 64(3), 429. 458.

Smiskova-Gustafsson, H. (2013). Chunks in L2 Development: A usage based perspective. Groningen: Grodil.

Stengers, H., Boers, F., Housen, A., \& Eyckmans, J. (2011). Formulaic sequences and L2 oral proficiency: Does the type of target language influence the association? International Review of Applied Linguistics, 49, 321-343.

Tang, J. (2012). An empirical study on the effectiveness of the lexical approach to improving writing in SLA. Journal of Language Teaching $\mathcal{E}$ Research, 3(3), 578-583.

Tyler, A. E., \& Ortega, L. (2018). Usage-inspired L2 instruction. In A. Tyler, L. Ortega, M. Uno, \& H.I. Park (Eds.). Usage-Inspired L2 Instruction (pp. 3-26). Amsterdam: John Benjamins Publishing Company. 
Tyler, A. E., Ortega, L., Uno, M., \& Park, H. I. (Eds.). (2018). Usage-inspired L2 instruction: Researched pedagogy (Vol. 49). Amsterdam: John Benjamins Publishing Company.

Vasiljevic, Z. (2014). Teaching collocations in a second language: Why, what and how. ELTA Journal, 2(2), 48-73.

Willis, D. (1990). The lexical syllabus: A new approach to language teaching. London: Harper Collins Publishers.

Wood, D. (2006). Uses and functions of formulaic sequences in second language speech: An exploration of the foundations of fluency. Canadian Modern Language Review, 63(1), 13-33.

Wood, D. (2010). Formulaic language and second language speech fluency: Background, evidence and classroom applications. New York: Continuum.

Wray, A. (2002). Formulaic language and the lexicon. Cambridge: Cambridge University Press.

Wu, K. (2015). The effect of teaching collocations on the students' perceptions toward language learning. Studies in English Language Teaching, 3(3), 215-236.

\section{Appendix.}

\section{Sample activities in the LA group}

1) Read the following clues. Find and underline...

a. A sentence to ask where a place is

b. An expression to express that someone's opportunities started to decrease.

c. A sentence to say that someone took a longer path.

d. An action performed in a car.

e. A sentence to describe the physical appearance of a woman.

f. A sentence to express someone's worry about a future event.

2) Can you create more clues? Write 3 more clues to describe sentences from the lyrics. Then, tell them to your classmate. Check if he/she can guess.
a.
b.
c. 
3) Complete the following sentences from the song. Try it without looking at the lyrics. Do you remember the words?
a. I I you in the battleship.
b. When I her if I call her your name.
c. She was close, and she me very tightly.
d. I'm beginning to think I you all along.
e. I your scent on the seat belt.

4) Could you remember them? Now, use your dictionary and find more words to fill the gaps. Do they have the same meaning? Did the meaning of the sentence change?

Example:

a. I believed I watched you in the battleship.

b. She close, close enough to be your ghost.

c. When I her if I call her your name.

d. I over for a closer look.

e. She was close, and she me very tightly.

f. And I my lift home.

g. I'm beginning to think I you all along.

h. I your scent on the seat belt.

5) Find a song about past experiences and print the lyrics.

a. Create 3 clues to describe sentences in the lyrics.
i.
ii.
iii.

b. Tell the clues to your classmate while he/she is listening and reading the song. Can he/she guess them? 

role of formulaic sequences?

c. Find 3 sentences that describe past experiences and find synonyms for the verbs. Do not change the meaning of the sentence!

i.

ii.

iii. 